\title{
Design and Implementation of University Students Scientific Research Ability Evaluation System Based on Neural Network
}

\author{
Huilan Yin, ${ }^{1}$ Jing Zhang, ${ }^{2}$ Yanming Qi $\mathbb{D}^{1},{ }^{1}$ and Dongping Li ${ }^{3}{ }^{3}$ \\ ${ }^{1}$ School of Humanities and Law, Hebei University of Engineering, Handan 056038, China \\ ${ }^{2}$ Educational Technology Center, Hebei University of Engineering, Handan 056038, China \\ ${ }^{3}$ School of Civil Engineering, Hebei University of Engineering, Handan 056038, China \\ Correspondence should be addressed to Yanming Qi; qiyanming@hebeu.edu.cn
}

Received 18 December 2021; Accepted 26 January 2022; Published 18 February 2022

Academic Editor: Sheng Bin

Copyright ( $\odot 2022$ Huilan Yin et al. This is an open access article distributed under the Creative Commons Attribution License, which permits unrestricted use, distribution, and reproduction in any medium, provided the original work is properly cited.

\begin{abstract}
At present, many colleges attach more and more importance to the cultivation of scientific research ability of college students. However, there is no unified standard to effectively measure the cultivation effect. The current performance inference method cannot comprehensively evaluate the scientific research ability of college students. Few scholars have directly analyzed the college students' scientific research ability from the internal and external influencing factors. Therefore, this paper tries to design and implement a neural network analysis system for scientific research ability evaluation of college students. After surveying the status quo of scientific research ability evaluation of college students in northern China's Hebei Province, a hierarchical evaluation index system was constructed for college students' scientific research ability, referring to the existing evaluation index systems, and the weights were designed for the evaluation indices. Next, the backpropagation (BP) neural network was optimized by chaotic sinecosine grasshopper optimization algorithm (CSCGOA) and used to establish a neural network analysis system for scientific research ability evaluation of college students. The proposed system was proved effective through experiments. The relevant results effectively enhance the scientific level and accuracy of the evaluation of college students' scientific research ability, improve the cultivation of college students, and provide a scientific basis for colleges to understand the scientific research ability of their students.
\end{abstract}

\section{Introduction}

China attaches great importance to scientific and technological innovation. With the improvement of scientific and technological systems, the number of college research groups is growing through the campaign of scientific and technological innovation in colleges. The members of these groups must meet various scientific research and teaching requirements $[1-8]$. More college students need to participate in the innovation research of scientific and technological systems [9-11]. The atmosphere and tasks of the research teams can constantly stimulate the interest of college students in scientific research and continuously improve their literacy scientific research [12-16]. At present, many colleges attach more and more importance to the cultivation of scientific research ability of college students.
However, there is no unified standard to effectively measure the cultivation effect [17-24]. It is theoretically and practically significant to evaluate the students' scientific research ability, which guarantees the sustained healthy development of research activities in colleges.

The research and innovation ability of college students is constrained by various factors. Qi and Wang [25] developed a talent training model that effectively improves college students' research and innovation ability, analyzed the problems of the current talent training model, improved the evaluation index system for the research and innovation ability of college students, and combined entropy weight method with grey system theory to quantify their research and innovation ability. Based on fuzzy neural network, Yan and Zhao [26] established a three-level evaluation index system for researchers and evaluated their abilities of project 
demonstration, project development, and innovation ability, providing a reference for selecting the indices of college students' scientific research ability.

To a certain extent, the scientific research ability of college students depends on their innovation thinking and innovation ability. After deeply discussing the teaching model for cultivating students' innovation ability, Fang [27] deliberated on the origin, development model, and status quo of innovation education and concluded that innovation is motivated by innovation demand, under the model of innovation education. Drawing on the actual situation of School of Logistics Engineering, Wuhan University of Technology, Yang et al. [28] developed a base model, which relies on extracurricular scientific and technological innovation platforms to implement scientific research practices, to put forward training ideas, and to guide college students to enhance their basic scientific research literacy and integrated innovation ability.

Mass entrepreneurship and innovation is a national campaign of China. Zhang and Xi [29] proposed an evaluation model for the entrepreneurship and innovation thinking ability of college students based on a neural network, established a reasonable evaluation index system for their ideological and political education ability, preprocessed the evaluation indices through fuzzy analytic hierarchy process (FAHP), and built a fuzzy neural network (FNN) optimized by the rules of genetic algorithm (GA). The specific steps of the algorithm were given. Wang and Yan [30] proposed an extension model for evaluating students' ability cultivation and improvement: the problem was clearly defined as the evaluation of the cultivation and improvement of college students' innovation ability, an evaluation model was established to train and enhance that ability, the workflow of the model was explained, and the evaluation algorithm was designed in detail.

In the existing literature, there are rich studies about the evaluation of college students' scientific research ability. Most of them evaluated the ability through performance inference. But this approach is not very comprehensive. Few scholars have directly analyzed the college students' scientific research ability from the internal and external influencing factors. Data mining technology, which integrates the merits of artificial intelligence and big data analysis, has been widely applied in the field of evaluation, by virtue of its excellent prediction and estimation functions. Therefore, this paper attempts to design and implement a neural network analysis system for scientific research ability evaluation of college students. Firstly, Section 2 constructs a hierarchical evaluation index system for college students' scientific research ability, referring to the survey results on the status quo of scientific research ability evaluation of college students in northern China's Hebei Province, as well as the existing evaluation index systems. After that, the weights were designed for the evaluation indices. Next, Section 3 optimizes the backpropagation (BP) neural network by chaotic sine-cosine grasshopper optimization algorithm (CSCGOA) and uses the network to establish a neural network analysis system for scientific research ability evaluation of college students. The proposed system was proved effective through experiments.

\section{Evaluation Index System}

The scientific research ability of college students is affected by external factors like the research environment provided by the college and intrinsic factors like their own scientific research literacy. Figure 1 shows the structure of college students' intrinsic scientific research ability. The intrinsic scientific research ability of college students mainly covers three hierarchical dimensions: scientific cognition ability, scientific practice ability, and scientific innovation ability.

Chinese colleges create research environment mainly through two methods: relying on their own to build labs and working with enterprises and research institutes to establish joint experimental training bases, industrial science parks, and technology markets. But not every college in all regions enjoys the idea development conditions and scale for research environment.

Taking northern China's Hebei Province, for example, the colleges make limited use of the above methods for developing research environment. Only a few provincial key colleges, such as Hebei University, Yanshan University, and Hebei University of Technology, have succeeded in building transformation platforms of scientific research results, either relying on their own or working with enterprises and research institutes.

Among them, Hebei University is the only college in Hebei receiving supports from both the province and central ministries. The college has successfully founded 12 scientific enterprises, 5 cultural enterprises, and 6 other enterprises in association with other enterprises and research institutes. Only 7 independent innovation enterprises have settled in the industrial science park established by the college. The industry-university-research cooperation in Hebei is still in the infancy.

For college students, scientific research is an exploratory and innovative individual or collective activity to explore new knowledge in their discipline and solve the conflicts between set views of science and empirical evidence. Figure 2 summarizes the general process of scientific research by college students, which consists of such six phases: topic selection, experimental exploration, hypothesis development, practical test, theoretical system development, and results transformation. Each phase needs to be supported and comprehensively planned by a complete scientific research management mechanism. However, not every college in all regions boasts such a mechanism.

For example, the scientific research management mechanism of colleges in Hebei is not very complete. The current mechanism cannot cover every aspect of scientific research in colleges, such as project initiation, fund allocation, project implementation, and results transformation. Against this backdrop, the low degree of marketization of scientific research market bottlenecks the cultivation of college students' scientific research ability and hinders the integration of coastal economy of the province. In addition, the lack of unified measuring standards across the province hinders the appraisal and judgement of college students' scientific research ability within Hebei. If the economic value of research results is misjudged, it would be impossible for 


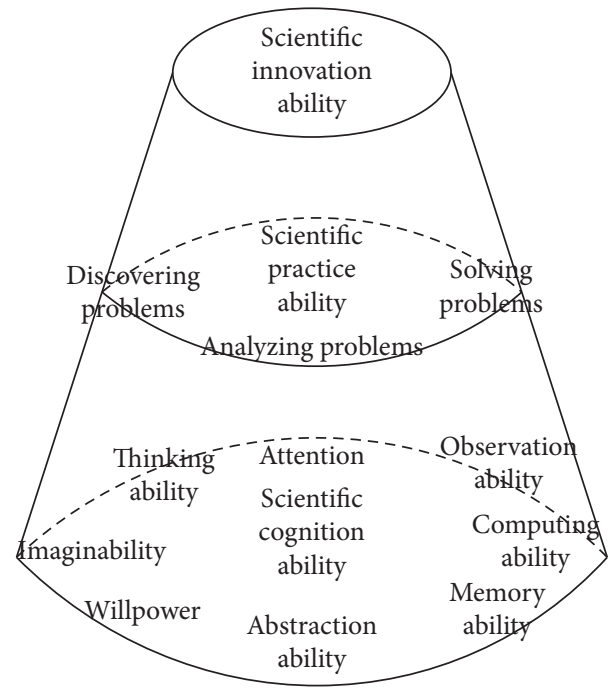

FIGURE 1: Structure of college students' intrinsic scientific research ability.

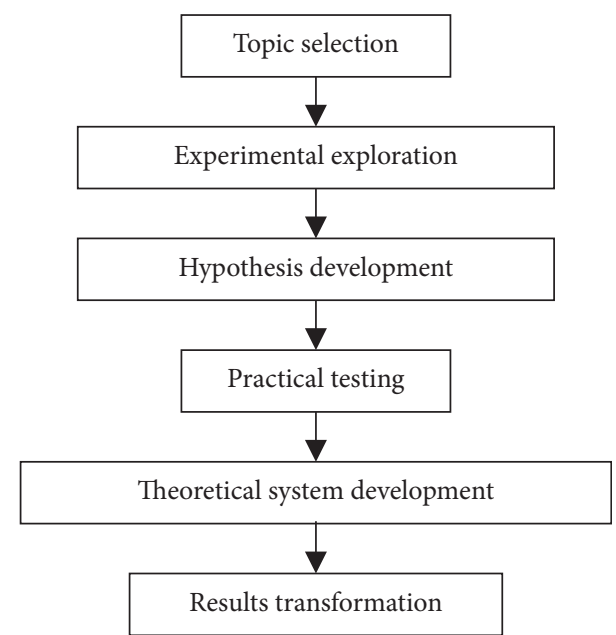

FIGURE 2: General process of scientific research by college students.

Hebei to rely on the research results to build a powerful coastal province.

Through the above analysis, a hierarchical evaluation index system was established for college students' scientific research ability, referring to the current state and existing evaluation index systems of scientific research among college students in Hebei.

2.1. Layer 1 (Primary Indices). $S R A=\left\{S R A_{1}, S R A_{2}, S R A_{3}\right.$, $\left.S R A_{3}\right\}=\{$ scientific cognition ability, scientific practice ability, scientific innovation ability, college research environment\};

2.2. Layer 2 (Secondary Indies). $S R A_{1}=\left\{S R A_{11}, S R A_{12}\right\}=$ \{ability to accept knowledge, ability to learn knowledge\};

$S R A_{2}=\left\{S R A_{21}, S R A_{22}, S R A_{23}\right\}=\{$ ability to discover problems, ability to analyze problems, ability to solve problems\};
$S R A_{3}=\left\{S R A_{31}, S R A_{32}, S R A_{33}, S R A_{34}, S R A_{35}\right\}=\{$ research papers, research books, invention patents, research projects, research rewards\};

$S R A_{4}=\left\{S R A_{41}, S R A_{42}, S R A_{43}, S R A_{44}\right\}=\{$ labs, joint experimental training bases, industrial science parks, senior researchers\};

2.3. Layer 3 (Tertiary Indices). $S R A_{11}=\left\{S R A_{111}, S R A_{112}\right.$, $\left.S R A_{113}, S R A_{114}, S R A_{115}\right\}=\{$ attention, observation ability, memory ability, abstraction ability, willpower $\}$;

$S R A_{12}=\left\{S R A_{121}, S R A_{122}, S R A_{123}, S R A_{124}, S R A_{125}\right\}=$ \{comprehension ability, thinking ability, computing ability, imaginability, sensibility\};

$S R A_{21}=\left\{S R A_{211}, S R A_{212}, S R A_{213}, S R A_{214}\right\}=\{$ information collection ability, information mining ability, information integration ability, decision-making ability\};

$S R A_{22}=\left\{S R A_{221}, S R A_{222}, S R A_{223}\right\}=\{$ experimental ability, practical ability, collaboration ability\};

$S R A_{23}=\left\{S R A_{231}, S R A_{232}, S R A_{233}\right\}=\{$ logic reasoning ability, empirical transfer ability, analysis and evaluation ability\};

$S R A_{31}=\left\{S R A_{311}, S R A_{312}, S R A_{313}\right\}=\{$ number of research papers, number of citations, impact factor of journals\};

$S R A_{32}=\left\{S R A_{321}\right\}=\{$ number of research books $\}$;

$S R A_{33}=\left\{S R A_{331}, S R A_{332}, S R A_{333}\right\}=\{$ number of invention patents, number of practical patents, number of appearance design patents $\}$;

$S R A_{34}=\left\{S R A_{341}, S R A_{342}, S R A_{343}, S R A_{344}\right\}=\{$ number of national research projects, number of provincial/ministerial research projects, number of municipal/departmental research projects\};

$S R A_{35}=\left\{S R A_{351}, S R A_{352}, S R A_{353}, S R A_{354}\right\}=\{$ number of national research rewards, number of provincial/ministerial research rewards, number of municipal/departmental research awards\};

$S R A_{41}=\left\{S R A_{411}, S R A_{412}\right\}=\{$ number of completed labs, number of labs under construction $\}$;

$S R A_{42}=\left\{S R A_{421}, S R A_{422}\right\}=\{$ number of completed joint experimental training bases, number of joint experimental training bases under construction $\}$;

$S R A_{43}=\left\{S R A_{431}, S R A_{432}\right\}=\{$ number of enterprises in cooperation, number of enterprises planned for cooperation\};

$S R A_{44}=\left\{S R A_{441}\right\}=\{$ number of senior researchers $\}$.

Based on the above evaluation index system, the hierarchy of scientific research ability evaluation for college students is plotted as Figure 3.

The weights of the above evaluation indices were designed by the principle of system optimization, subjective will of evaluators, and the objective situation of the college students.

Firstly, the judgement matrix is designed. Let $D_{1}, D_{2}, \ldots$, $D_{m}$ be the $m$ tertiary indices; $E I$ a secondary index; $\mu_{i}(i=1,2$, $\ldots, m)$ the importance of $D_{i}$ relative to EI. Then, we have

$$
\sum_{i=1}^{m} \mu_{i}=1
$$


where $\mu_{i}$ is the weight of $D_{i}$ relative to $E I$, that is, the importance of $D_{i}$ relative to $E I$. Then, the ratio $D_{i j}$ of the importance of $D_{i}$ relative to $E I$ to that of $D_{j}$ relative to $E I$ can be calculated by

$$
D_{i j}=\frac{\mu_{i}}{\mu_{j}} .
$$

The ratio of the importance of $D_{1}$ relative to $E I$ to that of $D_{i}$ relative to $E I$ and the ratio of the importance of $D_{1}$ relative to $E I$ to that of $D_{j}$ relative to $E I$ can be, respectively, obtained as

$$
\begin{aligned}
& D_{1 i}=\frac{\mu_{1}}{\mu_{i}}, \\
& D_{1 j}=\frac{\mu_{1}}{\mu_{j}} .
\end{aligned}
$$

Then, we have

$$
\frac{D_{1 i}}{D_{1 j}}=\frac{\left(\mu_{i} / \mu_{j}\right)}{\left(\mu_{1} / \mu_{i}\right)}=\frac{\mu_{1}}{\mu_{j}} \cdot \frac{\mu_{i}}{\mu_{1}}=\frac{\mu_{i}}{\mu_{j}}=D_{i j} .
$$

The value of $D_{i j}$ can be solved by comparing $D_{1}$ with every other factor $D_{2}, \ldots, D_{m}$. On this basis, the comparison matrix $D$ can be constructed as

$$
D=\left(\begin{array}{ccc}
D_{11} & \cdots & D_{1 m} \\
\vdots & \ddots & \vdots \\
D_{m 1} & \cdots & D_{m m}
\end{array}\right)
$$

The above analysis shows that when $i=j, D_{i j}$ is identically equal to 1 ; otherwise, $D_{i j}=1 / D_{j i}$; that is , $D_{i j}$ is the reciprocal of $D_{j i}$. Then, a symmetrically distributed reciprocal matrix can be established as

$$
D=\left(\begin{array}{ccc}
1 & \cdots & D_{1 m} \\
\vdots & \ddots & \vdots \\
\frac{1}{D_{m}} & \cdots & 1
\end{array}\right)=\left(\begin{array}{ccc}
\frac{\mu_{1}}{\mu_{1}} & \cdots & \frac{\mu_{1}}{\mu_{m}} \\
\vdots & \ddots & \vdots \\
\frac{\mu_{m}}{\mu_{1}} & \cdots & \frac{\mu_{m}}{\mu_{m}}
\end{array}\right),
$$

where all diagonal elements are equal to 1 ; the other elements are axially symmetrically distributed across the main diagonal. Since the weights of all indices add up to 1 , we have

$$
\frac{\mu_{1}}{\mu_{i}}+\frac{\mu_{2}}{\mu_{i}}+\ldots+\frac{\mu_{m}}{\mu_{i}}=\frac{\mu_{1}+\mu_{2}+\ldots \mu_{m}}{\mu_{i}}=\frac{1}{\mu_{i}} .
$$

After constructing the judgement matrix, the columns of the matrix can be added up to obtain $1 / \mu_{1}, 1 / \mu_{2}, \ldots, 1 / \mu_{m}$. The corresponding reciprocals are the weight coefficients $\mu_{1}$, $\mu_{2}, \ldots \mu_{m}$.

To weaken the subjective influence on index weighting, the above method was combined with the coefficient of variation method. The index weights obtained by both methods were synthetized in MATLAB language into the final integrated weight of each index (Figure 4).

\section{Neural Network Analysis System}

Our research problem aims to establish the nonlinear mapping from the evaluation indices to the evaluations of scientific research ability of college students. BP neural network is a common model for capacity evaluation. The network effectively optimizes the parameter update mode and works well in nonlinear mapping.

By ignoring the computing gradient, the network can be optimized to focus on the objective function or constraints. The optimized version is often adopted for prediction and identification tasks.

As shown in Figure 5, the BP neural network has three layers: an input layer, a hidden layer, and an output layer. Let $q_{1}, q_{2}, \ldots, q_{n}$ be the inputs; $w_{1}, w_{2}, \ldots, w_{m}$ the predictions; $\omega_{i j}$ the connection weight of input and hidden layers; $\omega_{j l}$ the connection weight of hidden and output layers; $n, m$, and $k$ the number of input nodes, output nodes, and hidden nodes, respectively; $o$ and $p$ the thresholds of the hidden layer and the output layer, respectively; $g$ the activation function of the hidden layer. Then, the outputs of the hidden layer and the output layer can be, respectively, expressed as

$$
\begin{aligned}
& F_{j}=g\left(\sum_{i=1}^{n} \omega_{i j} q_{i}-o_{j}\right), \quad j=1,2, \ldots, k, \\
& U_{k}=\sum_{j=1}^{k} F_{j} \omega_{j l}-p_{l}, \quad l=1,2, \ldots, m .
\end{aligned}
$$

The error between network output and expected output can be calculated by

$$
\varepsilon_{l}=w_{l}-U_{l}, \quad l=1,2, \ldots, m .
$$

Let $\delta$ be the learning rate. Based on the prediction error $\varepsilon_{l}$, network weights $\omega_{i j}$ and $\omega_{j l}$ can be updated by

$$
\begin{cases}\omega_{i j}=\omega_{i j}+\delta F_{j}\left(1-F_{j}\right) q_{i} \sum_{l=1}^{m} \omega_{j l} \varepsilon_{l}, & i=1,2, \ldots, n ; j=1,2, \ldots, k \\ \omega_{j l}=\omega_{j l}+\delta F_{j} \varepsilon_{l}, & j=1,2, \ldots, k ; l=1,2, \ldots, m .\end{cases}
$$


Based on the prediction error $\varepsilon_{l}$, network thresholds $o$ and $p$ can be updated by

$$
\begin{cases}o_{j}=o_{j}+\delta F_{j}\left(1-F_{j}\right) \sum_{l=1}^{m} \omega_{j l} \varepsilon_{l}, & j=1,2, \ldots, k, \\ p_{l}=p_{l}+e_{l} l=1,2, \ldots, m, & l=1,2, \ldots, m .\end{cases}
$$

Then, it is necessary to judge if the algorithm meets the termination condition. If not, the hidden layer output should be recalculated by formula (8).

Capable of simulating the swarm activities and interactions of grasshoppers, the grasshopper optimization algorithm (GOA) boasts ideal convergence speed and search efficiency and balances global search with local search. Let $Q_{i}$ be the current position of grasshopper $i ; E_{i}$ the social interaction force between swarms; $H_{i}$ the gravity of grasshopper $i ; O_{i}$ the wind advection. Then, the behaviors of the grasshopper swarm can be mathematically described as

$$
Q_{i}=E_{i}+H_{i}+O_{i}
$$

Let $\sigma_{i j}=\left|Q_{j}-Q_{i}\right|$ be the distance between grasshoppers $i$ and $j$; function $e$ the social interaction force; $M$ the number of grasshoppers. Then, $E_{i}$ can be expressed as

$$
E_{i}=\sum_{\substack{j=1 \\ j \neq i}}^{M} e\left(\sigma_{i j}\right) \vec{\sigma}_{i j}
$$

The unit direction vector pointing from grasshopper $i$ to grasshopper $j$ can be defined as

$$
\vec{\sigma}_{i j}=\frac{Q_{j}-Q_{i}}{\sigma_{i j}} \text {. }
$$

The gravity $H_{i}$ of grasshopper $i$ can be calculated by

$$
H_{i}=-h \vec{t}_{h}
$$

The value of $H_{i}$ is the product between the gravitational constant $h$ and the unit vector of the center of the Earth. Let $v$ be the air drift constant. Then, the current position $O_{i}$ of grasshopper $i$ can be calculated by

$$
O_{i}=v \vec{t}_{r}
$$

The value of $O_{i}$ is the product between $v$ and the unit vector of wind direction. The direction of the product is the same as the unit vector of wind direction. Substituting $E_{i}, H_{i}$, and $O_{i}$ separately into formula (12),

$$
Q_{i}=\sum_{\substack{i=1 \\ j \neq i}}^{M} e\left(\left|Q_{j}-Q_{i}\right|\right) \frac{Q_{j}-Q_{i}}{\sigma_{i j}}-h \vec{t}_{h}+v \vec{t}_{r} .
$$

If the grasshoppers reach the comfort zone quickly, then the swarm does not have enough time to converge to the designated position. Thus, formula (17) cannot be directly used to optimize the neural network. Let $\beta$ be the contraction factor. The following modification was carried out:

$Q_{i}^{\phi+1}=\beta\left\{\sum_{\substack{j=1 \\ j \neq i}}^{M} \beta \cdot \frac{v p-k p}{2} \cdot e\left(\left|Q_{j}^{\phi}-Q_{i}^{\phi}\right|\right) \cdot \frac{Q_{j}^{\phi}-Q_{i}^{\phi}}{\sigma_{i j}}\right\}+\vec{\psi}^{\phi}$.

Parameter $\beta$ was introduced to effectively reduce the comfort zone, repulsion zone, and attraction zone. Let $\varphi$ be the current number of iterations; $\varphi_{\max }$ the maximum number of iterations. Then, $\beta$ can be solved by

$$
\beta(\phi)=D_{\max }-\phi \cdot \frac{D_{\max }-D_{\min }}{\phi_{\max }} .
$$

Then, the distance of each grasshopper to the optimal grasshopper is calculated. The coordinates of grasshoppers $i$ and $j$ in the $\varphi$-th iteration can be denoted as $Q^{\varphi}{ }_{i}$ and $Q^{\varphi}{ }_{j}$, respectively; the distance between grasshoppers $i$ and $j$ in the $\varphi$-th iteration can be denoted as $\sigma^{\varphi}{ }_{i j}$; the upper and lower bounds can be denoted as $k p$ and $v p$, respectively; the optimal solution of the current model can be denoted as $\psi^{\varphi}$.

The social interaction function $e$ takes the grasshopper distance as the independent variable. Any change in the distance will alter the function value. Let $Q D$ and $F W$ be the intensity and range of the attraction, respectively. Then, function $e$ can be expressed as

$$
e(\sigma)=Q D \cdot t^{-G E / F W}-t^{-G E} .
$$

Let $Q^{\varphi}{ }_{i}$ be the position of grasshopper $i$ in the $\varphi$-th iteration; $V^{\varphi}{ }_{i}$ the current optimal position; $\tau_{1}$ the linear decrement function controlling the sine-cosine global search range. Then, the mathematical model based on sine-cosine optimization algorithm can be expressed as

$$
Q_{i}^{\phi+1}=\left\{\begin{array}{l}
Q_{i}^{\phi}+\tau_{1} \cdot \sin \left(\tau_{2}\right) \cdot\left|\tau_{3} V_{i}^{\phi}-Q_{i}^{\phi}\right|, \tau_{4}<0.5, \\
Q_{i}^{\phi}+\tau_{1} \cdot \cos \left(\tau_{2}\right) \cdot\left|\tau_{3} V_{i}^{\phi}-Q_{i}^{\phi}\right|, \tau_{4} \geq 0.5 .
\end{array}\right.
$$

Let $\varphi$ be the current number of iterations; $\psi$ the maximum number of iterations. Then, $\tau_{1}$ can be expressed as

$$
\tau_{1}=\gamma-\phi \cdot \frac{\gamma}{\psi}
$$

With the growing number of iterations, $\tau_{1}$ will decrease adaptively, and the search range will narrow down correspondingly. $\tau_{2}, \tau_{3}$, and $\tau_{4}$ are random numbers in $[0,2 \pi]$, $[-2,2]$, and $[0,1]$, respectively. Specifically, $\tau_{2}$ adaptively adjusts the balanced traversal of the swarm positions; $\tau_{3}$ 


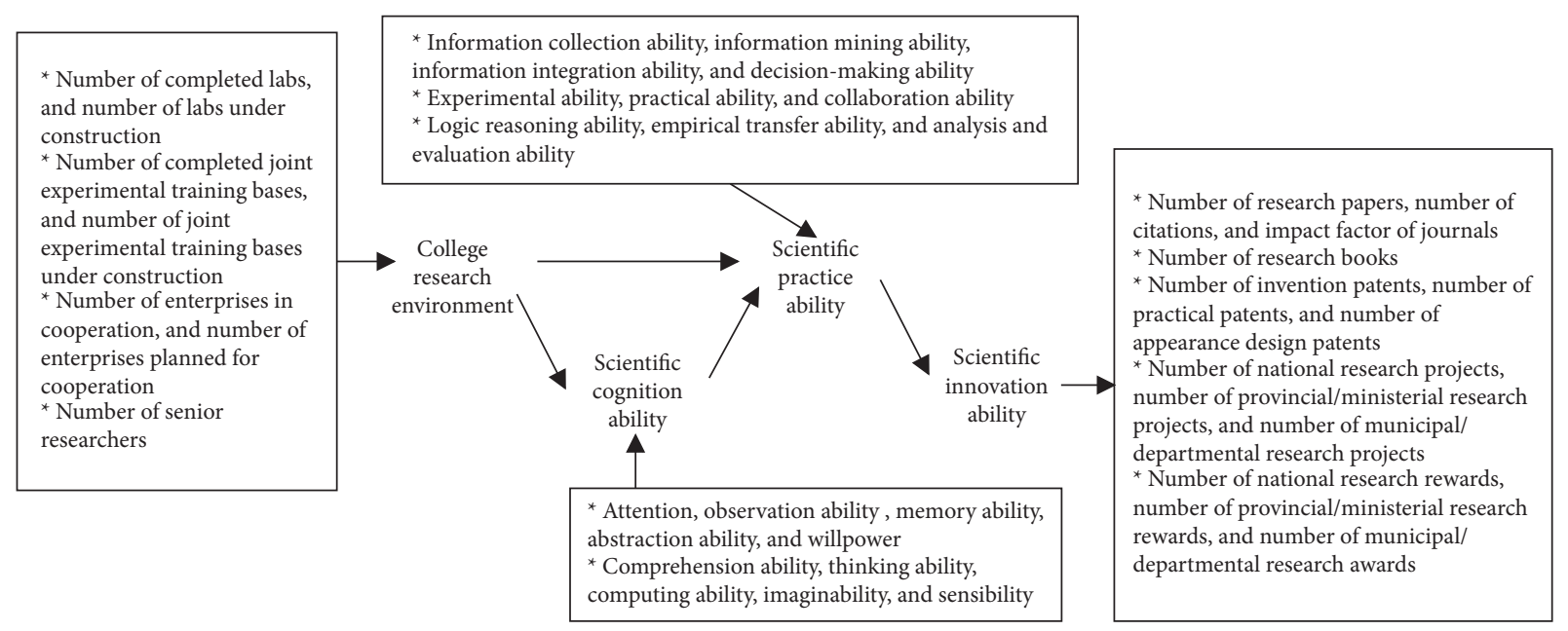

FIgURE 3: Hierarchy of scientific research ability evaluation for college students.

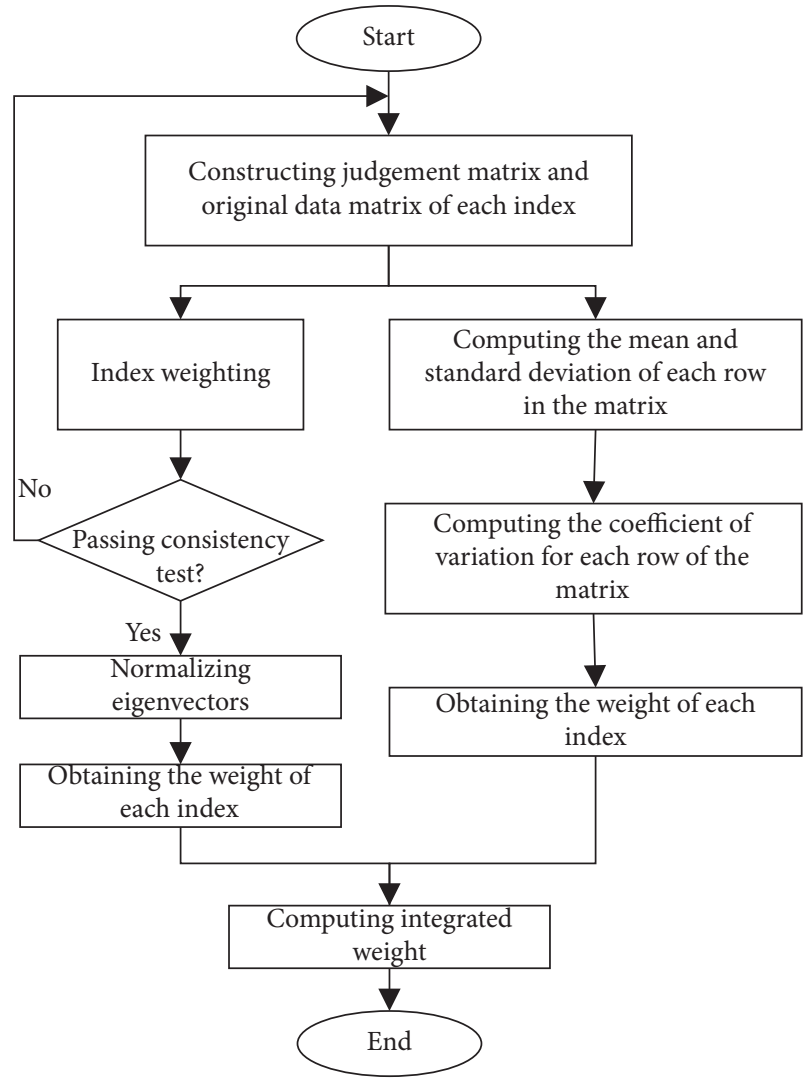

FIGURE 4: Flow of index weighting.

adaptively adjusts the individual positions; $\tau_{4}$ adaptively adjusts the degree of mutation of individual grasshoppers.

When it is applied to evaluate the scientific research ability of college students, the traditional BP neural network often falls into the local optimum trap, due to the selection of improper weights and thresholds. To quickly converge to the global optimal solution, this paper determines the weights and thresholds of the traditional BP neural network by the above CSCGOA. The improved model can be implemented in the following steps.
Step 1. Compute the covariance matrix of the index data, and ensure every element is a real value.

Step 2. Take the first row of the matrix as the network input.

Step 3. Determine the network topology based on the number of input and output layer parameters.

Step 4. Determine the grasshopper positions based on network weights and thresholds, and initialize the algorithm parameters, including the maximum number of iterations.

Step 5. Train the constructed network on the index data in the training set, and then estimate the index data in the test set. Let $M$ be the number of training samples; $w_{i}$ the actual value of sample $i ; w_{i}^{*}$ the output of sample $i$. Then, the fitness function can be defined as

$$
S U=\frac{1}{M} \sum_{i=1}^{M}\left(w_{i}-\hat{w}_{i}\right)^{2}
$$

Step 6. Update grasshopper positions and find the optimal individual. If the termination condition is satisfied, output the optimal value; otherwise, return to Step 4.

Step 7. Set the optimal parameters obtained by CSCGOA as the weights and thresholds of BP neural network, and obtain the evaluation model for college students' scientific research ability through network training.

\section{Experiments and Results Analysis}

The proposed BP neural network was optimized separately by gradient descent, quasi-Newton method, and our algorithm. By trial-and-error, the number of hidden layer nodes was determined according to the output errors under different numbers of such nodes. The BP neural network was modeled with the MATLAB neural network toolbox for the evaluation of scientific research ability of college students, with the maximum number of iterations being 1,000 . Table 1 


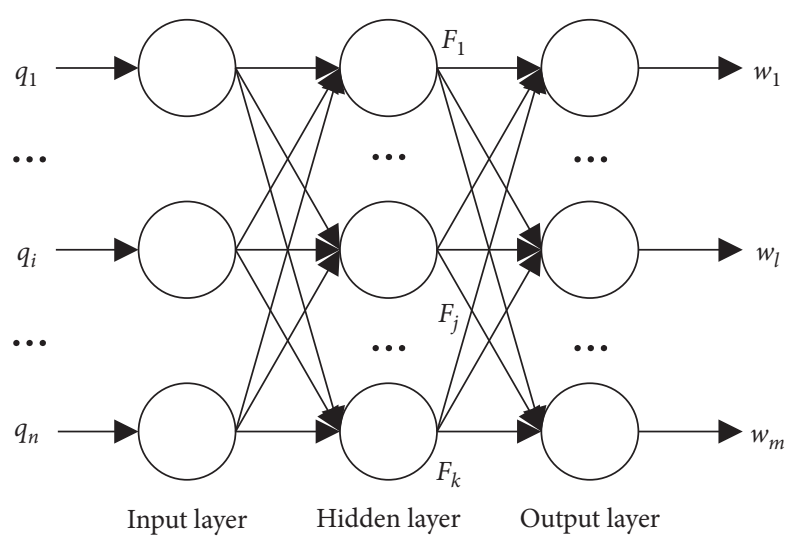

FIgURE 5: Network topology.

TABLE 1: Relationship between the number of hidden layer nodes and network error.

\begin{tabular}{lccc}
\hline Number of hidden layer nodes & Gradient descent & Quasi-Newton method & Our algorithm \\
\hline 1 & 0.358 & 0.0468 & 0.21 \\
2 & 0.215 & 0.357 & 0.325 \\
3 & 0.265 & 0.264 & 0.352 \\
4 & 0.0726 & 0.0207 & 0.186 \\
5 & 0.186 & 0.0357 & 0.24 \\
6 & 0.0214 & 0.154 & 0.268 \\
7 & 0.286 & 0.175 & 0.183 \\
8 & 0.212 & 0.318 & 0.0753 \\
9 & 0.324 & 0.0411 & 0.031 \\
10 & 0.0215 & 0.243 & 0.0856 \\
11 & 0.3 & 0.352 & 0.22 \\
12 & 0.386 & 0.237 & 0.0864 \\
13 & 0.163 & 0.213 & 0.142 \\
14 & 0.186 & 0.352 & 0.213 \\
\hline
\end{tabular}

presents the measured network errors under different numbers of hidden layer nodes. If there are too many nodes in the hidden layer, the network will suffer from overfitting. When the number of nodes in that layer was 10, the network errors of all three optimization methods were minimized. Therefore, the number of hidden layer nodes of our network model was set to 10 .

This paper verifies the performance of our model in the following aspects: the number of iterations, network error, generalization ability, and evaluation accuracy. Figure 6 shows the training performance curve of our network model. It can be seen that our model tended to converge at the $45^{\text {th }}$ iteration. The model training was terminated, when the maximum number of iterations was reached, or when the evaluation error reached the preset threshold. The network weights and thresholds were saved. The network model at this moment was treated as the optimal evaluation model for college students' scientific research ability.

Table 2 compares the predicted results of different models with the expected results. Note that the predicted results were obtained through weighted averaging of the weights obtained through combinatorial weighting. These weights were determined based on the opinions of experts in the relevant fields and the original data of the current state of the college students. The values are in line with the reality, and the evaluation results are scientific and realistic.
As shown in Table 2, the actual output of our model concerning the scientific research ability of college students was closer to the expected output than that of gradient descent and that of quasi-Newton method. The level of that ability output by our model was consistent with the expected level. The matching accuracy reached $100 \%$.

To verify the effectiveness of our improvement of GOA, the scientific research ability of college students was evaluated by traditional BP neural network, GOA-optimized BP neural network, and our network, respectively. Figure 7 shows the prediction error curves of the three models.

As shown in Figure 7, the three models differed greatly in prediction error. The traditional BP neural network and GOAoptimized BP neural network both saw mutations in evaluation results, which led to a large error. By contrast, the prediction error of our model fluctuated less significantly and oscillated about zero. Our model achieved a smaller prediction error than GOA-optimized BP neural network and traditional BP neural network. This means our model can evaluate the scientific research ability of college students very realistically.

Table 3 compares the MSE, root-mean-square-error (RMSE), and mean absolute error (MAE) of five prediction models: traditional BP neural network, BP neural network optimized by gradient descent, BP neural network optimized by quasi-Newton method, BP neural network optimized by GOA, and our network. 


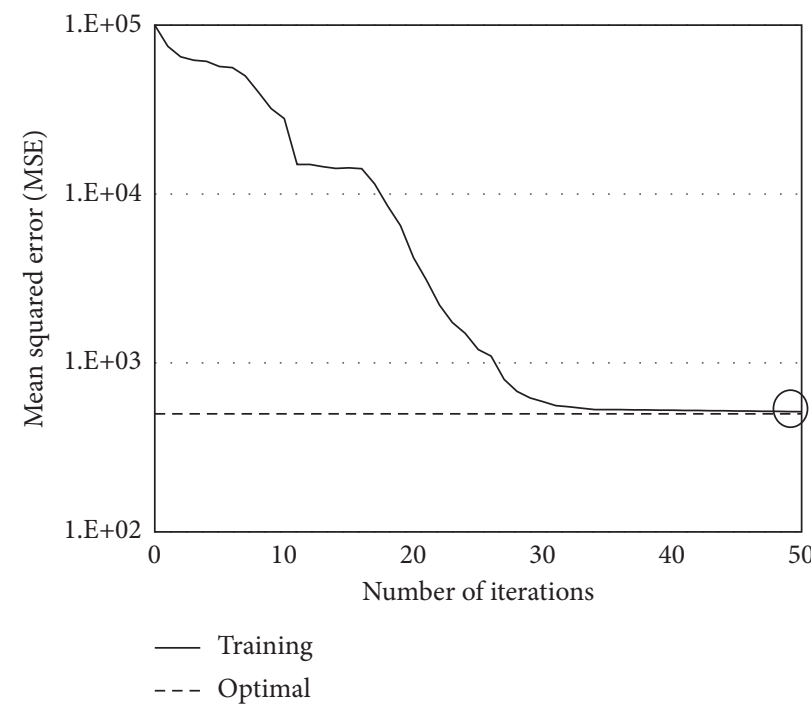

FIGURE 6: Training performance curve of our network model.

TABLE 2: Comparison of the predicted results of different models with the expected results.

\begin{tabular}{|c|c|c|c|c|c|c|c|c|c|}
\hline Expected results & $\begin{array}{l}\text { Expected output } \\
\text { Expected level }\end{array}$ & $\begin{array}{c}0.92 \\
\text { Excellent }\end{array}$ & $\begin{array}{c}0.91 \\
\text { Good }\end{array}$ & $\begin{array}{c}0.87 \\
\text { Excellent }\end{array}$ & $\begin{array}{c}0.88 \\
\text { Good }\end{array}$ & $\begin{array}{c}0.77 \\
\text { Excellent }\end{array}$ & $\begin{array}{c}0.93 \\
\text { Excellent }\end{array}$ & $\begin{array}{c}0.85 \\
\text { Excellent }\end{array}$ & $\begin{array}{c}0.84 \\
\text { Good }\end{array}$ \\
\hline $\mathrm{Gr}$ & $\begin{array}{c}\text { Actual output } \\
\text { Actual level } \\
\text { Matching? Yes/No }\end{array}$ & $\begin{array}{c}0.9358 \\
\text { Excellent } \\
\text { Yes }\end{array}$ & $\begin{array}{c}0.6857 \\
\text { Good } \\
\text { Yes }\end{array}$ & $\begin{array}{c}0.7584 \\
\text { Excellent } \\
\text { Yes }\end{array}$ & $\begin{array}{c}0.8628 \\
\text { Good } \\
\text { No }\end{array}$ & $\begin{array}{c}0.7628 \\
\text { Good } \\
\text { Yes }\end{array}$ & $\begin{array}{l}0.9225 \\
\text { Excellent } \\
\text { Yes }\end{array}$ & $\begin{array}{c}0.8728 \\
\text { Excellent } \\
\text { Yes }\end{array}$ & $\begin{array}{c}0.8357 \\
\text { Good } \\
\text { Yes }\end{array}$ \\
\hline Quasi-Newton & $\begin{array}{c}\text { output } \\
\text { level }\end{array}$ & $\begin{array}{c}0.8635 \\
\text { Excellent } \\
\text { Yes }\end{array}$ & $\begin{array}{c}0.6837 \\
\text { Good } \\
\text { Yes }\end{array}$ & $\begin{array}{c}0.7386 \\
\text { Excellent } \\
\text { Yes }\end{array}$ & $\begin{array}{c}0.8634 \\
\text { Good } \\
\text { No }\end{array}$ & $\begin{array}{c}0.7658 \\
\text { Excellent } \\
\text { Yes }\end{array}$ & $\begin{array}{c}0.9228 \\
\text { Good } \\
\text { Yes }\end{array}$ & $\begin{array}{c}0.9048 \\
\text { Excellent } \\
\text { Yes }\end{array}$ & $\begin{array}{c}0.8672 \\
\text { Excellent } \\
\text { No }\end{array}$ \\
\hline Our algorithm & $\begin{array}{c}\text { Expected level } \\
\text { Actual output } \\
\text { Actual level }\end{array}$ & $\begin{array}{c}0.9247 \\
\text { Excellent } \\
\text { Yes }\end{array}$ & $\begin{array}{c}0.9124 \\
\text { Good } \\
\text { Yes }\end{array}$ & $\begin{array}{c}0.8627 \\
\text { Excellent } \\
\text { Yes }\end{array}$ & $\begin{array}{c}0.8857 \\
\text { Good } \\
\text { Yes }\end{array}$ & $\begin{array}{c}0.7735 \\
\text { Excellent } \\
\text { Yes }\end{array}$ & $\begin{array}{c}0.9338 \\
\text { Excellent } \\
\text { Yes }\end{array}$ & $\begin{array}{c}0.8535 \\
\text { Excellent } \\
\text { Yes }\end{array}$ & $\begin{array}{c}0.8446 \\
\text { Good } \\
\text { Yes }\end{array}$ \\
\hline
\end{tabular}

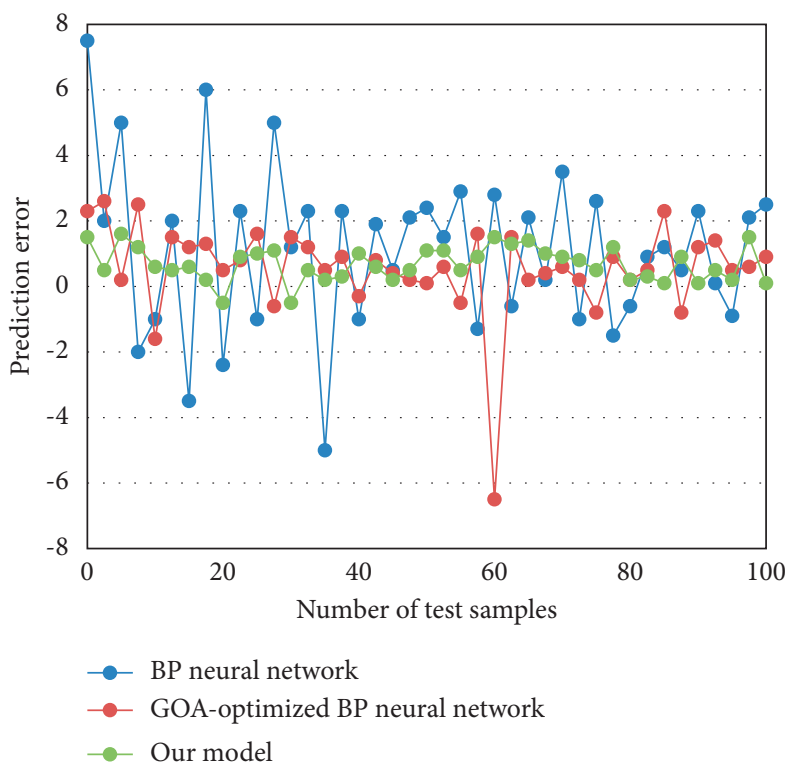

Figure 7: Prediction error curves of different models. 
TABLE 3: Evaluation errors of different prediction models.

\begin{tabular}{|c|c|c|c|c|c|c|}
\hline $\begin{array}{l}\text { Data } \\
\text { sources }\end{array}$ & $\begin{array}{c}\text { Error } \\
\text { metrics }\end{array}$ & $\begin{array}{c}\text { Traditional } \\
\text { network }\end{array}$ & $\begin{array}{c}\text { Network optimized by } \\
\text { gradient descent }\end{array}$ & $\begin{array}{l}\text { Network optimized by quasi- } \\
\text { Newton method }\end{array}$ & $\begin{array}{c}\text { Network optimized } \\
\text { by GOA }\end{array}$ & Our model \\
\hline \multirow{3}{*}{1} & MSE & 0.3257 & 0.3428 & 0.2786 & 0.3287 & 0.2238 \\
\hline & RMSE & 0.6258 & 0.5276 & 0.5376 & 0.5837 & 0.4834 \\
\hline & $M A E$ & 0.4853 & 0.4685 & 0.3825 & 0.4127 & 0.3658 \\
\hline \multirow{3}{*}{2} & MSE & 0.4615 & 0.3275 & 0.2685 & 0.4835 & 0.2385 \\
\hline & RMSE & 0.6813 & 0.5684 & 0.4752 & 0.6952 & 0.4537 \\
\hline & $M A E$ & 0.5368 & 0.4376 & 0.4576 & 0.5276 & 0.3864 \\
\hline
\end{tabular}

For object 1, our model achieved smaller MSE, RMSE, and MAE than all the other models. For object 2, our model and the network optimized by quasi-Newton method realized relatively low errors, while the other optimized networks performed poorly in the evaluation of college students' scientific research ability. Overall, our model has a high precision in predicting the scientific research ability of college students.

\section{Conclusions}

This paper designs and implements a neural network analysis system for scientific research ability evaluation of college students. Firstly, a hierarchical evaluation index system was constructed for college students' scientific research ability, and the index weighting method was designed in detail. After that, the BP neural network was optimized by CSCGOA, and a neural network analysis system was built up for scientific research ability evaluation of college students. Through experiments, the training performance of the proposed model was tested. The results demonstrate the convergence ability of the model. Then, the expected results of different models were compared with the predicted results, and the evaluation errors of different prediction models were contrasted, indicating that our model has a relatively high precision in predicting the scientific research ability of college students.

This research has formulated a feasible roadmap and achieved desired effects. However, several aspects need to be further improved. On the one hand, the evaluation indices should be further refined to realize more scientific evaluation of college students' scientific research ability. On the other hand, the evaluation contents need to be further analyzed and mined, with the growing volume of user data; the system function could be expanded by giving suggestions on how to develop a specific ability of the students based on the development trend of their abilities.

\section{Data Availability}

The data used to support the findings of this study are available from the corresponding author upon request.

\section{Conflicts of Interest}

The authors declare that they have no conflicts of interest.

\section{Acknowledgments}

The authors gratefully acknowledge the financial support from Hebei Social Science Foundation Project (HE21MK032).

\section{References}

[1] J. Budassi and M. Rafailovich, "The effect of university research apprenticeships for high school students on Science, Math, Engineering, and Technology learning and the pursuit of Science, Math, Engineering, and Technology degrees and careers," MRS Communications, vol. 8, no. 2, pp. 387-397, 2018.

[2] M. Leitner, N. N. Lam, F. Wang, L. Wang, S. Meng, and J. Kent, "Geographic information science and technology at Louisiana State University," Cartography and Geographic Information Science, vol. 42, no. s1, pp. 84-90, 2015.

[3] T. Akyurek and S. Usman, "Spent fuel interrogation using delayed fast neutron spectrum at Missouri University of Science and Technology Reactor," Progress in Nuclear Energy, vol. 85, pp. 525-540, 2015.

[4] W. Huang, Q. Zhang, and W. Tian, "Polymer science and technology research at northwestern polytechnical university," Macromolecular Rapid Communications, vol. 40, no. 17, p. 1970038, 2019.

[5] M. van Oostrom, J. A. Pedraza-Rodríguez, and M. FernándezEsquinas, "Does the location in a science and technology park influence university - industry relationships?" International Journal of Knowledge Management, vol. 15, no. 3, pp. 66-82, 2019.

[6] J. Lu, Y. Gao, X. Wang, C. Bai, B. Wang, and Z. Wu, "80 years education of aerospace science and technology in Tsinghua University," Chinese Journal of Aeronautics, vol. 31, no. 9, pp. 1797-1804, 2018.

[7] V. Sinha, A. Srivastava, and H. Koo Lee, "A novel method for NDT applications using NXCT system at the Missouri University of Science \& Technology," Nuclear Instruments and Methods in Physics Research Section A: Accelerators, Spectrometers, Detectors and Associated Equipment, vol. 750, pp. 43-55, 2014.

[8] M. Nakayama, "Case study of employment trends across 25 years of graduates of a Japanese Science and Technology University," European Journal of Engineering Education, vol. 39, no. 1, pp. 112-123, 2014.

[9] Y. Wang, T. Sun, Y. Bao, X. Ma, and Z. Liu, "Experiment study on elastic indicator of thermal shock ceramic materials-implementation of students' innovative research project of shandong university of science and technology," MATEC Web of Conferences, vol. 100, p. 05086, 2017.

[10] I. D. Gates, J. Wang, R. Kannaiyan, and Y. Su, "Instilling innovation and entrepreneurship in engineering graduate 
students: observations at the University of Calgary," Canadian Journal of Chemical Engineering, vol. 99, no. 10, pp. 2195-2204, 2021.

[11] P. I. Sandell, "Innovations in maritime research through cooperation between university and employer of the student writing his/her master thesis," in Proceedings of the 16th Annual General Assembly and Conference of the International Association of Maritime Universities, IAMU AGA, pp. 327-330, University of Rijeka, Croatia, October 2020.

[12] S. Qiang, "The influence of shared mental model on CoP performance: the instance of scientific research innovation team of university," Geomatics and Information Science of Wuhan University, vol. 37, no. s1, pp. 110-112, 2012.

[13] W. M. Zeng, "Research on the evolutionary processes of a university's scientific innovation team," Journal of Harbin Engineering University, vol. 30, no. 1, pp. 96-100, 2009.

[14] N. E. Davis and M. Hodges, "Tips for scientific communicators: how to become a member of the research team," in Proceedings of the Annual Conference Proceedings of Society for Technical Communication, p. 207, Fairfax, VA, USA, 1995.

[15] A. Masmoudi, E. Mezghani, H. Bellaaj, K. Drira, and M. Jmaiel, "A web-based knowledge management system for scientific research team," in Proceedings of the 2017 IEEE 26th International Conference on Enabling Technologies: Infrastructure for Collaborative Enterprises (WETICE), pp. 296-301, Poznan, Poland, June 2017.

[16] K. I. Belousov, D. A. Baranov, and N. L. Zelyanskaya, "A research team and its subject area: towards the question of the effective planning of scientific activities," Scientific and Technical Information Processing, vol. 41, no. 2, pp. 85-97, 2014.

[17] A. N. Shtanko, S. D. Kulik, and A. A. Kondakov, "Effective scientific personnel training in the field of modern computer technologies for the implementation of advanced research projects of the Megascience class," Journal of Physics: Conference Series, vol. 1685, no. 1, p. 012011, 2020.

[18] W. Bei and D. Liu, "Research on the evaluation system of university's scientific research achievement based on the innovation ability," International Review on Computers and Software, vol. 7, no. 5, pp. 2100-2105, 2012.

[19] C. Sun and X. Yang, "Research on the high-level talents training mode based on the innovation ability- High lights in the evaluation reports on the competitiveness of the world first-class universities and scientific research organizations," Geomatics and Information Science of Wuhan University, vol. 37, no. s1, pp. 209-212, 2012.

[20] C. L. Xue, G. Xin, H. Y. Cao, Z. Yi, S. Zhang, and W. Naili, "Features and routes of the cultivation of scientific research ability in undergraduate education stage of medical schools," Advanced Materials Research, vol. 271-273, pp. 1618-1623, 2011.

[21] J. Ebenezer, O. N. Kaya, and D. L. Ebenezer, "Engaging students in environmental research projects: perceptions of fluency with innovative technologies and levels of scientific inquiry abilities," Journal of Research in Science Teaching, vol. 48, no. 1, pp. 94-116, 2011.

[22] Y. He, "Research on computer application and cultivation of scientific thinking ability," Journal of Physics: Conference Series, vol. 1992, no. 3, Article ID 032086, 2021.

[23] C. Zhao and Z. Sun, "Study on the evaluation of scientific research ability of university teachers based on the mathematica software," in Proceedings of the 2021 2nd International Conference on Big Data and Informatization Education (ICBDIE), pp. 334-338, Hangzhou, China, April 2021.
[24] Y. Gu, J. Qian, and L. Yan, "Research on scientific research performance evaluation based on the innovation ability by computer science," in Proceedings of the 2020 International Conference on Computer Science and Management Technology (ICCSMT), pp. 183-186, Shanghai, China, November 2020.

[25] Y. Qi and J. Wang, "A talent cultivation model for improving the innovation ability of college students in scientific research," International Journal of Emerging Technologies in Learning (iJET), vol. 15, no. 18, pp. 151-164, 2020.

[26] X. Yan and J. Zhao, "Evaluation of scientific research ability of scientific research staff based on fuzzy neural network," in Proceedings of the 2018 IEEE 3rd International Conference on Cloud Computing and Big Data Analysis (ICCCBDA), pp. 126-130, Chengdu, China, April 2018.

[27] D. Fang, "Tutor teaching mode for strengthening the cultivation of college students' scientific research and innovation ability under the maker time," Agro Food Industry Hi-Tech, vol. 28, no. 1, pp. 1250-1254, 2017.

[28] T. T. Yang, S. Y. Hao, L. Wu, and Y. Gu, "Undergraduates' innovation ability training based on scientific research base," Advanced Materials Research, vol. 734-737, pp. 3382-3385, 2013.

[29] F. Zhang and L. Xi, "An evaluation model for the innovation and entrepreneurship thinking ability of college students based on neural network," International Journal of Emerging Technologies in Learning (iJET), vol. 16, no. 2, pp. 188-204, 2021.

[30] K. Wang and C. Yan, "An evaluation model for the cultivation and improvement of the innovation ability of college students," International Journal of Emerging Technologies in Learning (iJET), vol. 15, no. 17, pp. 181-194, 2020. 